\title{
Jorge Glusberg
}

Alfonso Castrillón Vizcarra

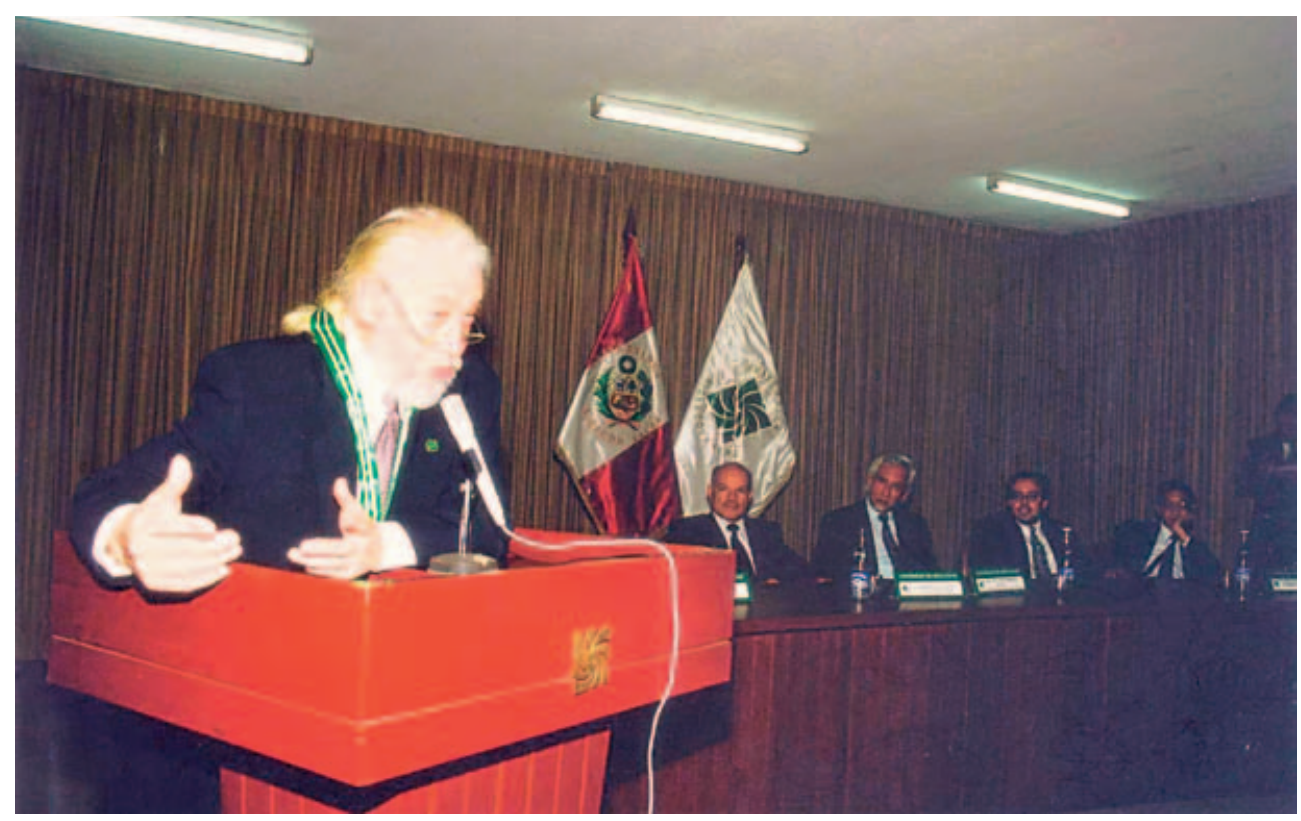

Jorge Glusberg dictando Conferencia Magistral, 1998.

En febrero de este año nos llegó la noticia de la muerte de Jorge Glusberg (Buenos Aires, 1932-2012) y, como sucede en estos casos y de manera rapidísima, recordamos los pasajes de su vida que lo ligaron al Perú. Hizo escala en Lima en 1977, luego de uno de esos viajes increíbles que unían las capitales más distantes de tierra, y me dijo: “¿Querés hacer un Festival de Video Arte?" Abrió una gran maleta y fue sacando, uno a uno, los cassettes con los nombres de Nan June Paik, Wolf Vostell y Hervé Fischer. Me parecía increíble. Por aquella época yo era Director de la Galería de Exposiciones del Banco Continental, y, por supuesto, no demoré la respuesta. El VIII Festival Internacional de Video Arte (y Primero en Lima), fue un éxito de público que colmó por un mes la galería de exposiciones.

Más tarde, en 1998 y en colaboración con ATA (Alta Tecnología Andina) realizamos el segundo Festival Internacional, donde Glusberg propició la participación de la sección argentina. Recuerdo que, como un evento importante programado para el Festival, nuestra universidad y su rector, Doctor Iván Rodríguez Chávez, le concedieron la distinción de Profesor Honorario.

Por esos años Glusberg ya era un hombre reconocido y comprometido seriamente con la cultura de su país. En 1968 había fundado el CAYC de Buenos Aires, era Presidente de la Sección Argentina de la Asociación Internacional de Críticos de Arte (AICA, 1978-81), 
co-fundador y Director del Comité Internacional de Críticos de Arquitectura (CICA) y Director del International Center of Advanced Studies in Art (ICASA) de la Universidad de Nueva York. Firmante de la Carta de Machu Picchu (1977), Medalla de Oro en la Bienal de Arquitectura de Sofía (Bulgaria) 1981, por el libro "Hacia una crítica de la arquitectura". Se hizo acreedor de la Orden del Mérito por Servicios Distinguidos en Grado de Comendador otorgado por el Presidente Arquitecto Fernando Belaunde Terry.

Autor de numerosos libros sobre las artes visuales y la arquitectura argentina, dedicó también un estudio relacionado con nuestra cultura titulado "Del hábitat incaico a la Lima del futuro" publicado en 1979 y libros de teoría como "Sociosemiótica de la arquitectura", publicado en 1978.

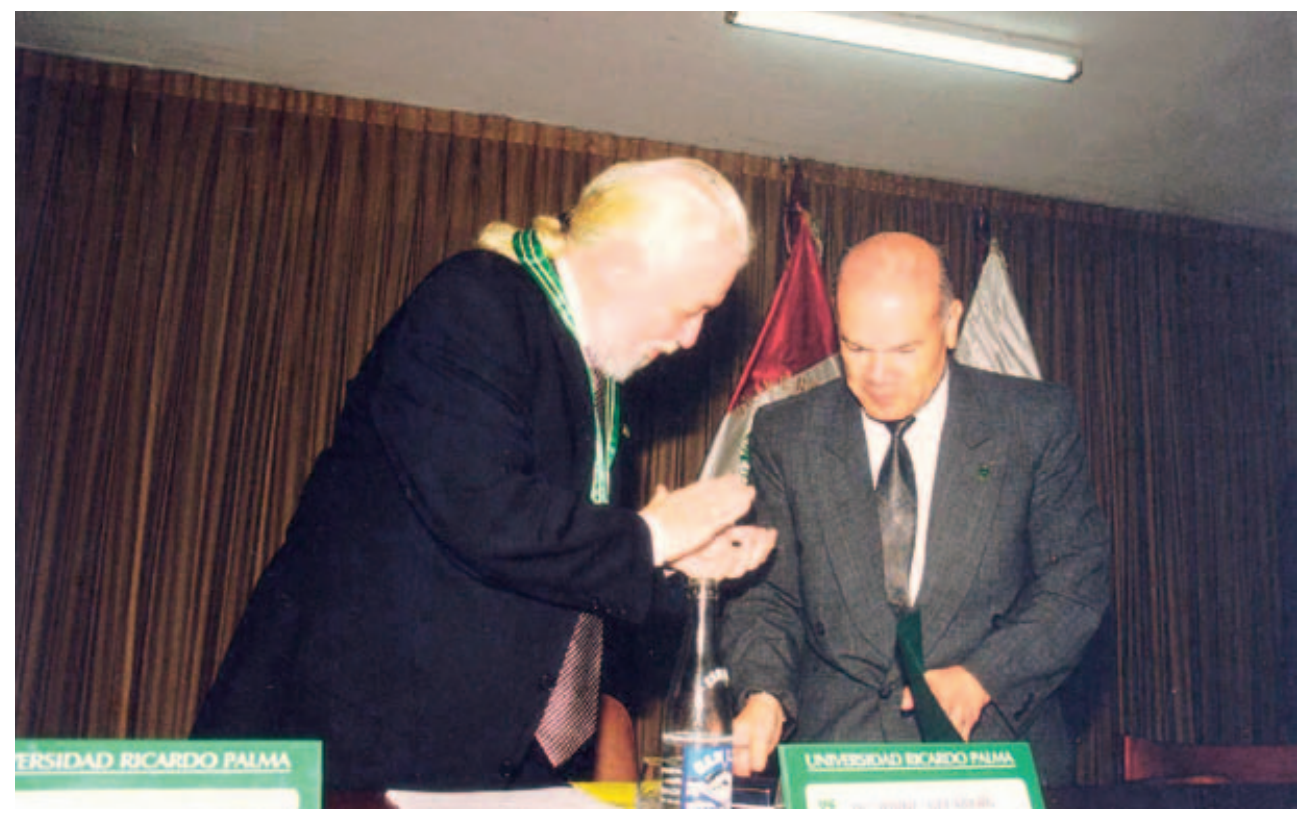

Rector de la URP, Dr. Iván Rodríguez Chávez, entregándole la distinción de Profesor Honorario a Jorge Glusberg. 1998.

Fue Director del Museo de Bellas Artes de Buenos Aires de 1994 al 2003, con programas que llevaron al museo a uno de los niveles más altos de gestión, pero que a la vez le trajeron una serie de problemas y amargura. Un hombre de la notoriedad de Glusberg tuvo buenos amigos en todo el mundo, pero también, como era natural, no faltaron los enemigos, provocados por su carácter franco y libérrimo, "sin pelos en la lengua” como reza el dicho popular. Lo que nadie le puede negar, ni sus más pugnases enemigos, es la acción cultural que llevó a cabo en Buenos Aires, luego del desaparecido Instituto Torcuato Di Tella, que puso nuevamente a la capital del Plata en un lugar destacado de América Latina. Según Fabián Lebenglik, Glusberg "ha sido una pieza clave de las artes visuales argentinas y de la presencia del arte local en el mundo”. 